\title{
Evidence of new species for malaria vector Anopheles nuneztovari sensu lato in the Brazilian Amazon region
}

\author{
Vera Margarete Scarpassa ${ }^{1,2^{*}}$, Antonio Saulo Cunha-Machado² and José Ferreira Saraiva ${ }^{2}$
}

\begin{abstract}
Background: Anopheles nuneztovari sensu lato comprises cryptic species in northern South America, and the Brazilian populations encompass distinct genetic lineages within the Brazilian Amazon region. This study investigated, based on two molecular markers, whether these lineages might actually deserve species status.

Methods: Specimens were collected in five localities of the Brazilian Amazon, including Manaus, Careiro Castanho and Autazes, in the State of Amazonas; Tucuruí, in the State of Pará; and Abacate da Pedreira, in the State of Amapá, and analysed for the $\mathrm{CO}$ gene (Barcode region) and 12 microsatellite loci. Phylogenetic analyses were performed using the maximum likelihood (ML) approach. Intra and inter samples genetic diversity were estimated using population genetics analyses, and the genetic groups were identified by means of the ML, Bayesian and factorial correspondence analyses and the Bayesian analysis of population structure.

Results: The Barcode region dataset $(\mathrm{N}=103)$ generated 27 haplotypes. The haplotype network suggested three lineages. The ML tree retrieved five monophyletic groups. Group I clustered all specimens from Manaus and Careiro Castanho, the majority of Autazes and a few from Abacate da Pedreira. Group II clustered most of the specimens from Abacate da Pedreira and a few from Autazes and Tucuruí. Group III clustered only specimens from Tucuruí (lineage III), strongly supported (97\%). Groups IV and V clustered specimens of A. nuneztovari s.s. and A. dunhami, strongly (98\%) and weakly (70 \%) supported, respectively. In the second phylogenetic analysis, the sequences from GenBank, identified as A. goeldii, clustered to groups I and II, but not to group III. Genetic distances (Kimura-2 parameters) among the groups ranged from $1.60 \%$ (between I and II) to $2.32 \%$ (between I and III). Microsatellite data revealed very high intra-population genetic variability. Genetic distances showed the highest and significant values $(P=0.005)$ between Tucuruí and all the other samples, and between Abacate da Pedreira and all the other samples. Genetic distances, Bayesian (Structure and BAPS) analyses and FCA suggested three distinct biological groups, supporting the barcode region results.
\end{abstract}

Conclusions: The two markers revealed three genetic lineages for A. nuneztovari s.l. in the Brazilian Amazon region. Lineages I and II may represent genetically distinct groups or species within A. goeldii. Lineage III may represent a new species, distinct from the A. goeldii group, and may be the most ancestral in the Brazilian Amazon. They may have differences in Plasmodium susceptibility and should therefore be investigated further.

Keywords: Cryptic species complex, Evolutionary genetics, Molecular entomology, Malaria vector

\footnotetext{
*Correspondence: vera@inpa.gov.br

${ }^{1}$ Laboratório de Genética de Populações e Evolução de Mosquitos

Vetores de Malária e Dengue, Coordenação de Biodiversidade, Instituto

Nacional de Pesquisas da Amazônia (INPA), Avenida André Araujo, 2936.

Bairro Petrópolis, Manaus, Amazonas 69067-375, Brazil

Full list of author information is available at the end of the article
} 


\section{Background}

Anopheles nuneztovari sensu lato was originally described in San Carlos, State of Cojedes, western Venezuela. It is geographically distributed from eastern Panama to northern South America [1] and is considered one of the four most important malaria vectors in northern South America, together with $A$. darlingi, A. albimanus and $A$. aquasalis $[2,3]$. Anopheles nuneztovari s.l. has been long recognized to be an important human malaria vector in Colombia and Venezuela, presenting endo and exophagic behaviours, besides high levels of anthropophily and infection rate $[4,5]$. Differently from Colombia and Venezuela, the Brazilian populations of this species, which are predominantly zoophagic, were not considered a malaria vector in past decades (1940s-1970s). However, with the development of more sensitive techniques for detecting malaria parasites, A. nuneztovari s.l. has been reported to be infected with Plasmodium species in five states of the Brazilian Amazon region [6-12], and was recently considered an important local vector in the State of Amapá, Brazil [12]. Supporting these findings, experimental infection studies conducted with $A$. nuneztovari s.l. from Manaus (MN), Brazil, reported a high infection rate for Plasmodium vivax [13]. In fact, the "populations" of the Brazilian Amazon region feed preferentially on bovines rather than humans, and this behaviour is probably the limiting factor to transmitting human malaria [12].

In view of its importance as malaria vector in northern South America, a great number of studies was conducted with A. nuneztovari s.l. from Colombia/Venezuela (malaria vector) and the Amazon Basin (non-malaria vector) [14-24], aiming to understand the distinct patterns of malaria transmission across its geographic range. The results indicated that $A$. nuneztovari s.l. could encompass two ecologically and genetically distinctive geographic populations, but no strong evidence of one cryptic species complex-as previously thought-was found, reflecting a very recent evolutionary history [14-24].

Based on phylogenetic analyses of three molecular markers and the comparison of the male genitalia aedeagus apex, Calado et al. [25] demonstrated that the A. nuneztovari from Colombia and Venezuela are likely to be distinct from the Brazilian Amazon specimens studied by the authors [25]. Considering these results, $A$. goeldii was revalidated from synonymy with $A$. nuneztovari [25]. Scarpassa [26] observed differences in the length of the pre-humeral dark spot (PHD) and the length of the subcostal pale spot (SCP) on the wings of the adult females from Buenaventura and Tibú (Colombia) compared with the specimens of the Brazilian Amazon, and-based on a taxonomic key-they were identified as $A$. rangeli.
However, the 4th instar larvae, male genitalia and eggs were identified as A. nuneztovari. Sant'Ana et al. [27] reported similar findings in the revision of $A$. goeldii. Recently, A. dunhami was also included in A. nuneztovari s.l., based on phylogenetic analyses performed with three markers [28]. Thus, the taxonomic status of A. nuneztovari s.l. now includes: $A$. nuneztovari s.s. which occurs in Colombia and western Venezuela, A. goeldii in the Brazilian Amazon region, and A. dunhami, found in the Brazilian Amazon [25, 29-31] and Colombia [32]. In the Brazilian Amazon, however, A. dunhami shows overlap with $A$. goeldii in a large geographic area [31]. The role of A. nuneztovari s.s. as malaria vector has been elucidated, but the role of each lineage and/or A. goeldii species within the Brazilian Amazon still remains to be clarified, despite the reports of infection by Plasmodium spp. [612]. Anopheles dunhami is abundant in forests and has zoophilic behaviour [33], and it was never found infected with the malaria parasite, or was wrongly identified as $A$. goeldii or other A. nuneztovari s.l. lineages.

Along with the presence of three cryptic species in A. nuneztovari s.l., two genetic lineages were reported in the Brazilian Amazon, based on ITS2 sequences [17] and mtDNA-RFLP [18, 23]. More recently, Mirabello and Conn [24] detected five lineages with the white gene, three of which (1, 4 and 5) in the Brazilian Amazon + Suriname, and two (2 and 3) in Colombia/Venezuela. The two lineages observed in Colombia and Venezuela could correspond to A. nuneztovari s.s., whereas the three of the Brazilian Amazon + Suriname could correspond to A. goeldii [24]. Scarpassa and Conn [31] proposed the existence of four lineages across its geographic range, based on the fragment at the $3^{\prime}$ end of the COI gene. Specimens from Bolivia/Colombia/Venezuela grouped to a single cluster (subclade II-C), and may represent $A$. nuneztovari s.s. The specimens from the Brazilian Amazon + Suriname grouped to three clusters (Clade I and subclades II-A and II-B) and may represent A. goeldii and other species within A. nuneztovari s.l. The inconsistence in the number of lineages among studies $[17,18,23,24,31]$ could be related especially to sampling strategies within the Brazilian Amazon region.

Given the evidence above, there is no doubt that $A$. nuneztovari consists of a cryptic species complex in northern South America, and that the Brazilian populations comprise two or more genetic lineages or species. Therefore, analyses with multi-markers will be needed to test the hypothesis of multiple species in the Brazilian Amazon region. The definition of these lineages could help understanding how they contribute to the malaria transmission in this region, especially because they may show differences in ecology, behavior and Plasmodium 
susceptibility, with consequent implications on management, surveillance and control measures. The aim of this study was to investigate whether the A. nuneztovari s.l. lineages detected [17, 18, 23, 24, 31] should actually have species status, based on the analyses of specimens from five localities of the Brazilian Amazon with the mitochondrial (barcode region) and nuclear (12 microsatellites loci) markers. Two of the five localities [Autazes (AU), Abacate da Pedreira (AP)] were sampled for the first time in this study, whereas the other localities [MN, Careiro Castanho (CS), Tucuruí (TU)] were previously studied by Scarpassa and Conn [31], using a fragment of the $3^{\prime}$ end of the COI gene. This fragment has demonstrated to be highly variable in anopheline species, being therefore amply used in the population genetics and phylogeographic studies of this group [34]. In contrast, the barcode region (Folmer region) that consists of a $648 \mathrm{bp}$ fragment at the $5^{\prime}$ end of the COI gene has emerged as the standard barcode region, because it presents a low rate of intra-specific and high inter-specific variation (barcoding gap), thus permitting the characterization of each taxonomic group or unit [35]. This region has shown to be a valuable tool in the identification of species complexes in anophelines [36-38]. The microsatellite markers, developed and characterized previously for A. nuneztovari s.l. [39, 40], were analysed for the first time in the present study. These markers are appropriate to estimate intra-population genetic diversity, fine-scale population structure, and also for taxonomic and evolutionary genetic studies of very recently evolved species. In the present study, the samples analysed were named $A$. nuneztovari s.l.

\section{Methods}

\section{Sample collection}

Anopheles nuneztovari s.l. specimens were collected in five localities of the Brazilian Amazon region (Table 1; Fig. 1), as follow: MN, CS and AU in the State of Amazonas; TU in the State of Pará; and AP in the State of Amapá, Brazil. All information regarding collection data, State, coordinates and sample size for each marker is shown in Table 1. The localities of MN, CS and AU are situated in the central region of the Brazilian Amazon, TU in the east and AP in the northeast. The collections were authorized by the Brazilian Institute for the Environment and Renewable Natural Resources (IBAMA) and by the System of Authorization and Information in Biodiversity (SISBIO), license number 38440-1 awarded to VMS.

Adult female mosquitoes were collected with Shannon traps and/or while resting on cattle corrals, transferred into labelled cups and transported to the laboratory. At the laboratory, the mosquitoes (females) were individually isolated in plastic cups for egg laying and the offspring were reared until they became adults. The morphological identification was done on adults (females) and eggs, as described in Faran [1] and Cova-Garcia [41]. Specimens were preserved in ethanol $95 \%$ and stored at $-20{ }^{\circ} \mathrm{C}$ or dried and stored at $-80{ }^{\circ} \mathrm{C}$ until DNA extraction.

\section{DNA extraction, PCR and sequencing}

Genomic DNA was extracted individually from whole mosquitoes, using the phenol and chloroform method [42], resuspended in $30 \mu \mathrm{L}$ of $1 \times \mathrm{TE}$ buffer $(10 \mathrm{mM}$

Table 1 Information on the Anopheles nuneztovari s.l. collection sites in the Brazilian Amazon region and Sitronela, in Colombia

\begin{tabular}{|c|c|c|c|c|c|}
\hline Localities, state & Abbreviation & Coordinates (Lat., long.) & Sample size COI & Sample size MSTL & Collection date \\
\hline Manaus, Amazonas & MN & $03^{\circ} 03^{\prime} \mathrm{S} ; 59^{\circ} 51^{\prime} \mathrm{W}$ & 12 & 32 & June, 2010 \\
\hline Careiro Castanho, Amazonas & CS & $03^{\circ} 49^{\prime} \mathrm{S}, 60^{\circ} 21^{\prime} \mathrm{W}$ & 22 & 32 & July, 2010 \\
\hline Autazes, Amazonas & $\mathrm{AU}$ & $03^{\circ} 41^{\prime} \mathrm{S} ; 59^{\circ} 07^{\prime} \mathrm{W}$ & 27 & 32 & May, 2013 \\
\hline Tucuruí, Pará & TU & $03^{\circ} 42^{\prime} \mathrm{S}, 49^{\circ} 27^{\prime} \mathrm{W}$ & 14 & 32 & August and October, 1992 \\
\hline Abacate da Pedreira, Amapá & AP & $00^{\circ} 07^{\prime} \mathrm{S} ; 51^{\circ} 17^{\prime} \mathrm{W}$ & 28 & 32 & February, 2013 \\
\hline Subtotal & & & 103 & 160 & \\
\hline \multicolumn{6}{|l|}{ Anopheles nuneztovari s.s. ${ }^{a}$} \\
\hline Sitronela, Valle $e^{b}$ & SI & $03 \circ 49^{\prime} \mathrm{N}, 77^{\circ} 04^{\prime} \mathrm{W}$ & 8 & NA & June, 1994 \\
\hline \multicolumn{6}{|l|}{ Anopheles dunhami } \\
\hline Autazes, Amazonas & $\mathrm{AU}$ & $03^{\circ} 41^{\prime} \mathrm{S} ; 59 \circ 07^{\prime} \mathrm{W}$ & 2 & NA & May, 2013 \\
\hline Coari, Amazonas & $\mathrm{CO}$ & $04^{\circ} 05^{\prime} \mathrm{S}, 63^{\circ} 07^{\prime} \mathrm{W}$ & 1 & NA & June, 2002 \\
\hline Manaus, Amazonas & MN & $03^{\circ} 03^{\prime} \mathrm{S} ; 59^{\circ} 51^{\prime} \mathrm{W}$ & 1 & NA & June, 2013 \\
\hline Total & & & 115 & 160 & \\
\hline
\end{tabular}

COI Cytochrome oxidase, I subunit, MSTL microsatellites, NA not analysed

a Species included in the phylogenetics analyses and genetic distances analysis

b The Sitronela locality is situated in Buenaventura, Department del Valle, in Colombia 


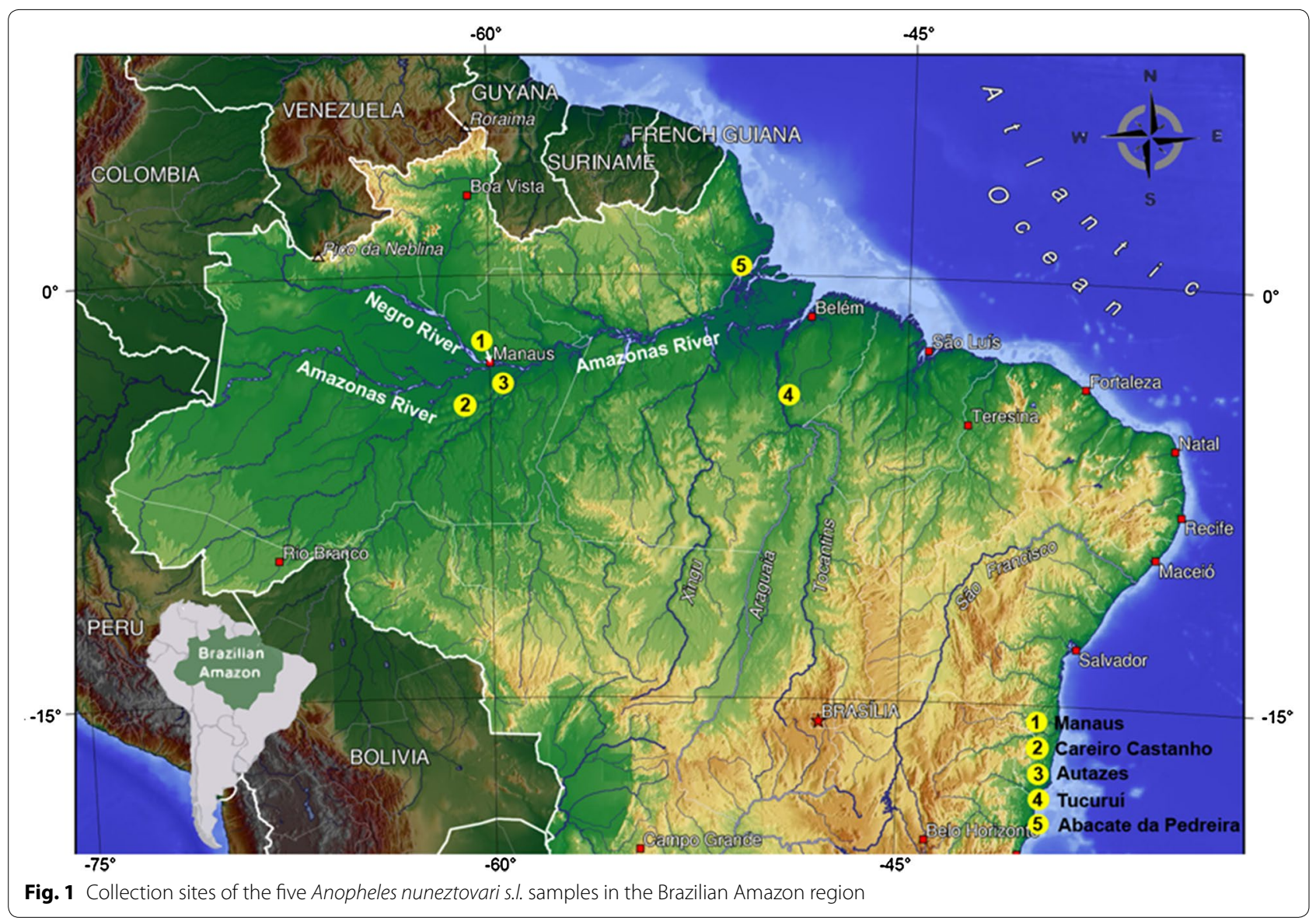

Tris-Cl pH 8.0, 1 mM EDTA pH 8.0) or sterile water, and then stored at $-80{ }^{\circ} \mathrm{C}$ until amplification by polymerase chain reaction (PCR) for the two markers.

For the mitochondrial DNA analyses, a 663 bp (base pair) fragment encompassing the barcode DNA region (Folmer region) of the COI gene of 103 individuals was amplified, as shown in Table 1 . The primers $(10 \mu \mathrm{M})$ used were LCO 1490 and HCO 2198 [43], and the amplification conditions were as described in Folmer et al. [43]. All PCR reactions included negative controls. The PCR products were visualized on $1 \%$ agarose gels under UV light and purified with PEG 8000. Both DNA strands of the purified PCR product were electro-injected into an automated ABI $3130 \mathrm{xl}$ Genetic Analyzer sequencer (Applied Biosystems, Thermo Fisher Scientific, Waltham, MA, USA), available at INPA (MN, Brazil).

\section{Microsatellite analyses}

In the microsatellite analyses, 32 specimens per locality were genotyped for the 12 loci under study (Table 1 ). Of these 12 loci, nine are described in Austin et al. [39]: Anu1, Anu4, Аnu6, Аnu9, Anu10, Anu12, Аnu14, Anu15 and Anu16; the other three are described in
Cunha-Machado and Scarpassa [40]: Anu22, Anu25 and $A n u 28$.

The microsatellite loci were amplified by PCR in a final volume of $10 \mu \mathrm{L}$ reaction solution containing 10-20 ng DNA template, $1.0 \mu \mathrm{L} 10 \times$ buffer, $2.1 \mu \mathrm{L} 1 \mathrm{mM}$ dNTPs, $0.3 \mu \mathrm{L} 50 \mathrm{mM} \mathrm{MgCl}, 0.4 \mu \mathrm{L} 4 \mathrm{mM} \mathrm{M} 13$-tailed forward primer [44], 0.4 $\mu \mathrm{L} 4 \mathrm{mM}$ M13-labelled primer (FAM, HEX and TAMRA), $0.8 \mu \mathrm{L} 4 \mathrm{mM}$ reverse primer, $0.2 \mu \mathrm{L}$ $5 \mathrm{U} / \mu \mathrm{L}$ Platinum Taq DNA Polymerase (Invitrogen Inc., Carlsbad, CA, USA), and 3.8 $\mu \mathrm{L}$ sterile water to complete the total volume. PCR was carried out in 2 steps: the first step consisted of denaturation $\left(68^{\circ} \mathrm{C}\right.$ for $2 \mathrm{~min}, 95^{\circ} \mathrm{C}$ for $30 \mathrm{~s})$ followed by 30 cycles of $35 \mathrm{~s}$ at $92{ }^{\circ} \mathrm{C}, 35 \mathrm{~s}$ at the primer-specific annealing temperature $[39,40]$, and $35 \mathrm{~s}$ at $72{ }^{\circ} \mathrm{C}$.

The second step consisted of 15 cycles of $30 \mathrm{~s}$ at $92{ }^{\circ} \mathrm{C}$, $35 \mathrm{~s}$ at $53{ }^{\circ} \mathrm{C}, 35 \mathrm{~s}$ at $72{ }^{\circ} \mathrm{C}$, followed by a final extension at $72{ }^{\circ} \mathrm{C}$ for $30 \mathrm{~min}$. The PCR fragments were analysed in an automated ABI 3130 xl Genetic Analyzer (Applied Biosystems, Thermo Fisher Scientific, Waltham, MA, USA), and the allele sizes were scored using GeneScan 500 ROX dye (Applied Biosystems) and genotyped in the GeneMapper version 4.0 (Applied Biosystems) program. 


\section{Statistical analyses}

\section{Barcode region analyses}

The forward and reverse sequences were automatically aligned in the Clustal W program and manually edited in Bioedit v. 7.0.8.0 [45], and the chromatograms were corrected using the electropherogram viewer Chromas Lite ${ }^{\circledR}$ [46]. The consensus sequences generated had a large ( 625 bp) region of overlap. The consensus sequences of each specimen were confirmed using BLAST (Basic Local Alignment Search Tool) [47]. The haplotypes were determined using the DnaSP v. 5.10 [48] and the TCS v. 1.21 [49] programs. Identical sequences were considered to be a single haplotype. To analyse population history patterns, a haplotype network was generated by means of a parsimony-based method that calculates the maximum number of mutational connections between pairs of sequences by the $95 \%$ parsimony criterion using the TCS program, v. 1.21 [49].

Phylogenetic relationships among the 27 haplotypes were inferred using the maximum likelihood (ML) method in the Mega program, v. 6 [50], with 1000 replicates. This analysis was performed using the general time reversible (GTR) $+\mathrm{G}+\mathrm{I}$ nucleotide substitution model, previously selected with the Akaike Information Criterion (AIC) in the jModelTest [51]. For this analysis, eight specimens of $A$. nuneztovari s.s. from Sitronela, Buenaventura, Colombia, and four specimens of $A$. dunhami from three localities of the Brazilian Amazon region (Table 1) were also sequenced. These sequences (haplotypes) together with the 27 haplotypes of this study were included as ingroup in the analysis. Sequences of $A$. oswaldoi species A were used as outgroup.

A second phylogenetic analysis was carried out using the 27 haplotypes of this study, two haplotypes of $A$. nuneztovari s.s., three haplotypes of $A$. dunhami and the sequences from other localities of the Brazilian Amazon region (EU848313-EU848332) published by Calado et al. [25] and Colombia (AF368078, AF368089, AF368094, AF368106, AF368115) available in GenBank. Our sequences had a length of $663 \mathrm{bp}$, whereas those of Calado et al. [25] were 493 bp long. To build the input file with two datasets, a fragment of $\sim 196 \mathrm{bp}$ from our sequences was removed, as well as a $\sim 15$ bp end fragment of the sequences from Calado et al. [25] and from GenBank. The final input file comprised sequences of $467 \mathrm{bp}$ in size, and therefore some informative sites were lost. This analysis was inferred using ML in Mega v. 6 [50] with the same parameters cited above. Sequences of $A$. oswaldoi species A were used as outgroup. A Bayesian inference (BI) analysis was attempted, but the tree topology was not well resolved; therefore, the results were not included in this study.

The intra-population and overall genetic diversity measurements, such as haplotype numbers $(N H)$, transition and transversion rates $(T \mathrm{~s} / T \mathrm{v})$, number of segregating sites $(N S)$, number of private sites (NPS), average number of nucleotide differences $(K)$, haplotype $(h)$ and nucleotide $(\pi)$ diversities, were estimated using the DnaSP v. 5.10 [48] and Arlequin v 3.1 [52] programs. Neutrality tests, Tajima's $D$ [53], Fu and Li's $D$ and $F$ [54] and Fu's Fs [55] were inferred in DnaSP v. 5.10 [48] and Arlequin, v 3.1 [52]. Tajima's $D$ [53], Fu and Li's $D$ and $F$ tests [54] were used to test the hypothesis that all mutations are selectively neutral. Tajima's $D$ test is based on the differences between the number of segregating sites and the average number of nucleotide differences. The $D$ and $F$ tests, proposed by $\mathrm{Fu}$ and $\mathrm{Li}$, are based on molecular polymorphism data. Fu's $F_{\mathrm{S}}$ test [55] assesses the haplotype structure based on the haplotype frequency distribution and was used as an additional neutrality test. This test is more powerful for detecting population expansion and genetic hitchhiking, whereas Tajima's $D$, $\mathrm{Fu}$ and Li's $F$ and $D$ tests are the most effective ones for detecting background selection.

Population genetic structure was estimated using traditional genetic differentiation measurements $\left(\Phi_{\mathrm{ST}}\right.$ pairwise) and hierarchical analysis of molecular variance (AMOVA). Both estimates were made in Arlequin, v.3.1 [52], and the significance level was inferred by permutation tests (10,000 replicates). AMOVA was performed on two different levels of population structure, to partition total molecular variance: (1) all samples (non-grouped) to test the overall differences among samples; and (2) to test the subdivision level between the central (MN, CS, AU) and eastern/northeastern (TU, AP) Brazilian Amazon regions.

The intra and inter-samples genetic distances of the five localities and among the three lineages were calculated using Mega v.6.0 [50], based on the Kimura-2 parameters (K-2P) evolutionary model. For these calculations, the lineages generated in Fig. 3 were used. The divergence time among the lineages was also calculated using the divergence sequence $\left(D_{x y}\right)$ and the mutation rate of $2.3 \%$ per million years [56], often estimated for mtDNA in insects. The haplotypes sequences of the five A. nuneztovari s.l. collection localities as well as those of $A$. nuneztovari s.s. and $A$. dunhami generated in this study are deposited in GenBank under accession numbers: KU865529 to KU865555 (H1 to H27), KU865556 to KU865557 (H28, H29) and KU865558 to KU865561 (H30 to H33).

\section{Microsatellite analyses}

The dataset was checked in the Micro-Checker v.2.2.3 [57] to detect potential errors that might have occurred at each locus during the genotyping, such as stuttering, large allele dropouts and null alleles. Whenever null alleles occurred, their frequencies were calculated in the same program. The intra-population genetic diversity 
measurements, such as the observed $\left(H_{\mathrm{O}}\right)$ and expected $\left(H_{\mathrm{E}}\right)$ heterozygosities, the Hardy-Weinberg equilibrium (HWE) and linkage disequilibrium $(L D)$ were estimated using Arlequin, v.3.1 [52]. The number of alleles per locus $\left(N_{\mathrm{A}}\right)$ and number of private alleles were calculated in Genalex, v.6.41 [58], whereas the inbreeding coefficient $\left(F_{\mathrm{IS}}\right)$ and allele richness $\left(A_{\mathrm{R}}\right)$ were estimated in Fstat, v.2.9.3 [59].

The genetic structure was accessed using pairwise $F_{\mathrm{ST}}$ and AMOVA. Both analyses were estimated in Arlequin, v.3.1 [52], with significance levels of 10,000 permutations. In the AMOVA test, the same hierarchical levels estimated for the Barcode region were used for the microsatellite data, as described above.

The STRUCTURE program, v. 2.3 [60], was used through a Bayesian approach to test the population structure among the samples. This method distinguishes clusters of genetically similar individuals from multilocus genotypes, without prior knowledge of their population affinities and origin, assuming an admixture model that allows individuals to have ancestors from more than one biological group. The model assumes $K$ genetic clusters, each one having a characteristic set of allele frequencies at each locus. Thus, an admixture model with correlated allele frequencies was assumed. The analysis was performed for genetic clusters $(K)$ ranging in number from 1 to 6 . Consistent results across runs were obtained using a burn-in period of 100,000 permutations, followed by 1000.000 Markov Chain Monte Carlo (MCMC) repeats. The true number of populations is expected to be the value of $K$ that maximizes the estimated model log-likelihood, $\log [\mathrm{P}(\mathrm{X} \mid \mathrm{K})][61]$. For the most likely value of $K$, the proportion of allocation $(Q)$ of the localities sampled within detected groups and the individual allocation ratio $q$ (proportion of ancestral genome of each specimen in the group) were estimated. Furthermore, the genetic structure was accessed by factorial correspondence analysis (FCA) that used the individual multilocus scores, computed in the Genetix program [62]. The genetic structure was again accessed by Bayesian analysis of population structure (BAPS) [63]. In this analysis, 1-5 clusters were employed (the upper corresponding to the total number of sampled localities), and five independent runs were implemented. The most probable genetic cluster configuration was prepared by comparing the log-likelihood values of the best models.

The Bonferroni correction [64] was applied to $P$ values in all the statistical analyses of this study that involved multiple comparisons.

\section{Results}

\section{Barcode region analysis}

The dataset consisted of 103 sequences with a fragment size of $663 \mathrm{bp}$ (Table 1). The amino acid translations revealed no stop codons, ensuring the absence of nonfunctional genes (pseudogenes) in the dataset. All sequences had 39 variable sites, 35 of which were parsimoniously informative. Of the 94 nucleotide substitutions, 87 $(92.55 \%)$ were transitions and seven $(7.45 \%)$ transversions. The nucleotide composition was rich in $\mathrm{A}+\mathrm{T}$ (Mean $=67.70 \%$ ), especially in the third codon position (92\%). In this study, there was evidence of heteroplasmy in two of the 16 individuals (12\%) from TU. Double picks (adenine/guanine) were observed at position 435 of the consensus sequences, and in both forward and reverse sequences. These sequences were excluded from the statistical analyses; therefore, the sample size from TU consisted of $\mathrm{n}=14$ (Table 1 ).

Of the 27 haplotypes observed, seven $(25.93 \%)$ were shared among samples and $20(74.07 \%)$ were singletons and/or exclusive of each sample (Table 2). Autazes had the largest number of haplotypes (10) and MN the lowest (5). Haplotypes H1 (likely the ancestral), H3 and H19 were the most common. $\mathrm{H} 1$ and $\mathrm{H} 3$ were shared among the three samples from the State of Amazonas. H19 was shared by 13 specimens from AP and two from TU. The sample from TU did not share haplotypes with three samples from the State of Amazonas (Table 2; Fig. 2).

The haplotype network (Fig. 2) suggested three lineages. Lineage I comprised most haplotypes from MN, CS and $\mathrm{AU}$ and few haplotypes from $\mathrm{AP}(\mathrm{H} 4=3$ specimens; $\mathrm{H} 11=1$ specimen). Lineage II clustered haplotypes from all samples, including two of the most common haplotypes (H3 and H19). Lineage III consisted only of haplotypes from TU $(\mathrm{H} 16-\mathrm{H} 18, \mathrm{H} 21-\mathrm{H} 23=11$ specimens), which was separated from lineages I and II by 11-16 mutational steps and by 9-12 mutational steps, respectively.

Table 2 Haplotype frequency observed for the $\mathrm{COI}$ gene (Barcode region) in the five Anopheles nuneztovari s.l. samples from the Brazilian Amazon region

\begin{tabular}{|c|c|c|}
\hline Samples & $N$ & Haplotype frequency \\
\hline Manaus & 12 & $H 1(6), H 2(2), H 3(1), H 4(1), H 5(2)$ \\
\hline Careiro Castanho & 22 & $\mathrm{H} 1(4), \mathrm{H} 3(4), \mathrm{H} 4(2), \mathrm{H} 5(1), \mathrm{H} 6(4), \mathrm{H} 7(5), \mathrm{H} 8(2)$ \\
\hline Autazes & 27 & $\begin{array}{l}H 1(10), H 3(6), H 4(1), H 9(2), H 10(3), H 11(1), \\
\quad H 12(1), H 13(1), H 14(1), H 15(1)\end{array}$ \\
\hline Tucuruí & 14 & $\begin{array}{l}\mathrm{H} 16(4), \mathrm{H} 17(2), \mathrm{H} 18(1), H 19(2), H 20(1), H 21(2), \\
\quad H 22(1), H 23(1)\end{array}$ \\
\hline Abacate da Pedreira & 28 & $\begin{array}{l}H 4(3), H 9(1), H 11(1), H 19(13), H 24(2), H 25(4) \\
\quad H 26(2), H 27(2)\end{array}$ \\
\hline Total & 103 & \\
\hline
\end{tabular}

In parentheses, number of individuals observed for each haplotype. The italics haplotypes are shared among samples

$N$ number of specimens sequenced 


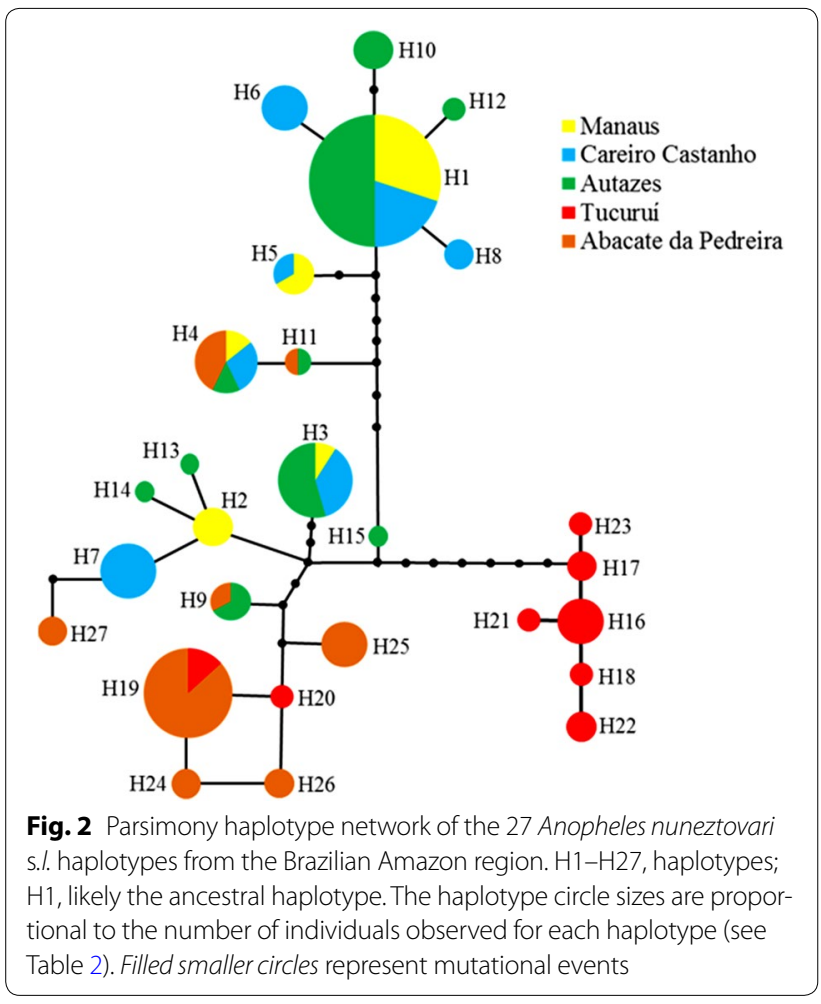

The ML tree retrieved five groups (Fig. 3) suggesting monophyly. Groups I and II were weakly supported. Group I clustered all specimens from MN and CS, most of those from $\mathrm{AU}$ and six specimens $(\mathrm{H} 4, \mathrm{H} 11, \mathrm{H} 26)$ from AP. Group II clustered most of the specimens from AP, two specimens (H9) from AU and three $(\mathrm{H} 19, \mathrm{H} 20)$ from TU. Group III clustered only specimens from TU (lineage III) and was strongly supported (97\%). Haplotypes of $A$. nuneztovari s.s. and $A$. dunhami clustered in separated branches, with 98 and $70 \%$ bootstrap support, respectively. Groups I and II generated in this analysis did not correspond to lineages I and II visualized in the haplotype network (Fig. 2); this discrepancy may be explained by little resolution of these groups in the ML tree (weakly supported), likely due to the small number of informative sites between them for this marker.

In the second phylogenetic analysis (Additional file 1), in which the sequences downloaded from GenBank were included, the ML tree retrieved six monophyletic groups. All sequences identified as $A$. goeldii from GenBank clustered with the haplotypes of groups I and II of this study (Fig. 3), forming three distinct groups (I, III, V), but all weakly supported. In the internal group, A. dunhami (group VI) constituted a sister group of the monophyletic clade formed by $A$. goeldii (Groups I, III, V), A. nuneztovari s.s. (Group II) and group IV (lineage III of this study). Of the three $A$. goeldii groups, group $\mathrm{V}$ is likely

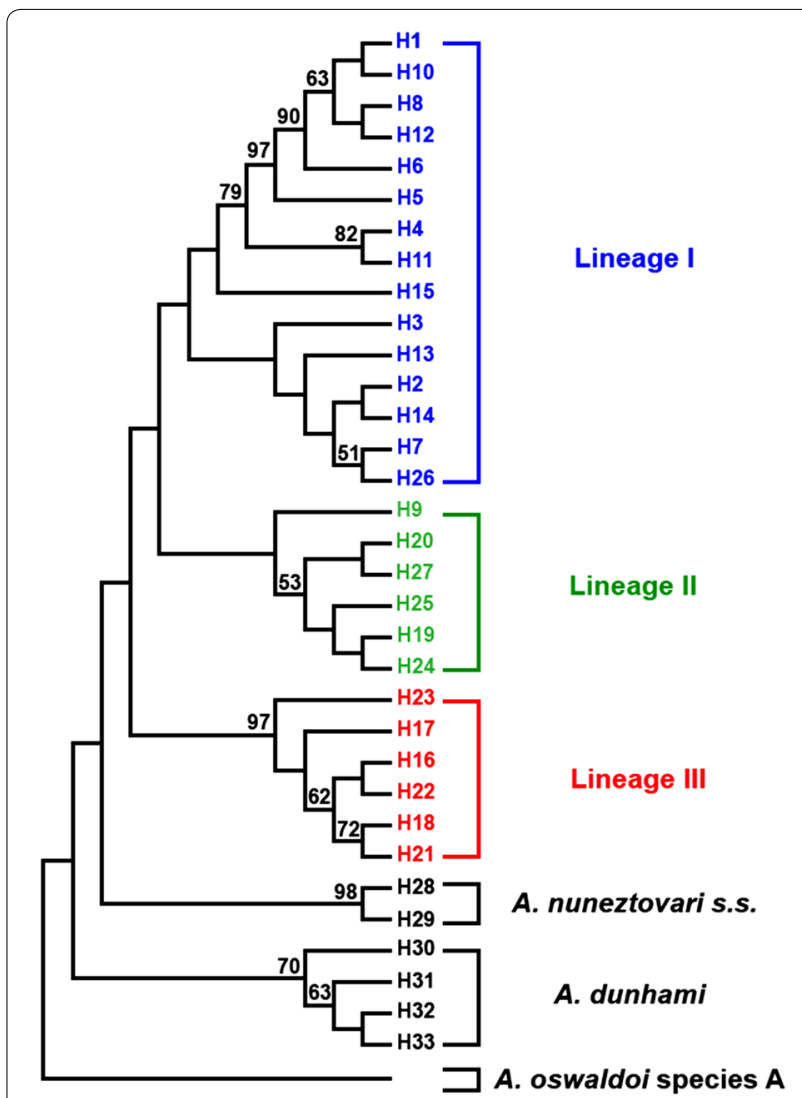

Fig. 3 Maximum Likelihood (ML) topology tree of the 27 Anopheles nuneztovari s.l. haplotypes from the Brazilian Amazon region, two Anopheles nuneztovari s.s. haplotypes $(\mathrm{H} 28, \mathrm{H} 29$, both from Sitronela, Colombia; see Table 1) and four Anopheles dunhami haplotypes (H30 from AU, H31 from Coari, H32 from MN, H33 from AU; see Table 1), using the GTR + I + G nucleotide substitution model. Values above each branch represent bootstrap support. Anopheles oswaldoi species A was used as outgroup

the most basal one and may actually be a distinct species. This group is a sister group to a monophyletic clade formed by groups I and III (A. goeldii), and II (A. nuneztovari s.s.) and IV (lineage III). This topology suggests that $A$. goeldii does not have an exclusive ancestry and could be paraphyletic. Groups I and III (A. goeldii) and II (A. nuneztovari s.s.) formed a monophyletic clade that is a sister group of group IV. The latter was well supported $(88 \%)$ and may also represent a distinct species. In this context, A. goeldii (groups I and III) could be a synonym of A. nuneztovari s.s. (group II), or A. goeldii (group I) could be a synonym of $A$. nuneztovari s.s. and A. goeldii (group III), a distinct species, or even each group could be a distinct species. Both trees were rooted using $A$. oswaldoi species A as outgroup.

Table 3 shows the intra-sample genetic diversity measurements. The haplotype diversity ranged from $0.742 \pm 0.116(\mathrm{MN})$ to $0.901 \pm 0.058$ (TU). The 
Table 3 Intra-population genetic diversity and neutrality tests estimated for the COI gene in the five Anopheles nuneztovari s.l. samples from the Brazilian Amazon region

\begin{tabular}{|c|c|c|c|c|c|c|c|c|c|c|c|}
\hline Samples & $T \mathrm{~s} / T \mathrm{v}$ & NH & $S$ & NPS & $K$ & $H \pm S D$ & $\pi \pm \mathrm{SD}$ & Tajima's D & Fu and Li's $D$ & Fu and Li's $F$ & Fu's Fs \\
\hline Manaus & $17 / 2$ & 5 & 19 & 0 & 6.44 & $0.742 \pm 0.116$ & $0.00971 \pm 0.00207$ & 0.1028 & 0.1943 & 0.1939 & 3.020 \\
\hline Careiro Castanho & $20 / 2$ & 7 & 22 & 2 & 8.00 & $0.870 \pm 0.033$ & $0.01207 \pm 0.00082$ & 1.2233 & 1.1029 & 1.3288 & $4.082^{*}$ \\
\hline Autazes & $20 / 2$ & 10 & 22 & 4 & 7.66 & $0.818 \pm 0.056$ & $0.01155 \pm 0.00089$ & 1.2271 & 1.0867 & 1.3266 & 1.767 \\
\hline Tucuruí & $15 / 0$ & 8 & 15 & 9 & 5.20 & $0.901 \pm 0.058$ & $0.00784 \pm 0.00198$ & 0.4159 & 0.9133 & 0.8925 & -0.321 \\
\hline Abacate da Pedreira & $15 / 1$ & 8 & 16 & 1 & 3.99 & $0.762 \pm 0.073$ & $0.00601 \pm 0.00129$ & -0.1046 & 1.1925 & 0.9242 & 0.907 \\
\hline Total & $17.4 / 1.4$ & 27 & 39 & 3.20 & 9.28 & $0.9210 \pm 0.014$ & $0.01399 \pm 0.00042$ & 0.7419 & 0.9768 & 1.0586 & -1.260 \\
\hline
\end{tabular}

$T s / T v$ transitions/transversions, NH Number of haplotypes, $S$ Number of segregating sites, NPS Number of private sites, $K$ Average number of nucleotide differences, $H \pm \mathrm{SD}$ and $\pi \pm \mathrm{SD}$ Haplotype and nucleotide diversities, respectively, with respective standard deviations (SD)

* $P<0.05$

nucleotide diversity ranged from $0.00601 \pm 0.00129$ (AP) to $0.01207 \pm 0.00082$ (CS). Tucuruí had the highest number of private sites (9); in the other samples it varied from $0(\mathrm{MN})$ to $4(\mathrm{AU})$. Table 3 also shows the neutrality tests for the five samples and total data. None of these tests produced statistically significant results, except for the sample from CS, for which Fu's Fs test was positive and significant $(4.082 ; P<0.05)$, indicating balancing selection, recent bottleneck or cryptic population structure.

Low genetic differentiation $\left(\Phi_{\mathrm{ST}}=-0.01162\right.$ to $-0.01975)$ and extensive gene flow ( $N \mathrm{~m}=$ infinity) were observed among the three samples from the State of Amazonas, indicating genetic homogeneity (data not shown). In contrast, great and significant genetic differentiation was found between $\mathrm{MN} / \mathrm{CS}$ / $\mathrm{AU}$ and TU $\left(\Phi_{\mathrm{ST}}=0.5988 ; 0.5146 ; 0.5231\right.$, respectively; $P=0.00000 \pm 0.0000)$ and between $\mathrm{MN} / \mathrm{CS} / \mathrm{AU} / \mathrm{TU}$ and $\operatorname{AP}\left(\Phi_{\mathrm{ST}}=0.5376 ; 0.4141 ; 0.4116 ; 0.5459\right.$, respectively; $P=0.00000 \pm 0.0000)$. In all comparisons, the $\mathrm{Nm}$ values were $<1$, suggesting absence of gene flow. AMOVA analysis including all samples also revealed significant structure between groups $\left(\Phi_{\mathrm{ST}}=0.3800\right.$; $P=0.00000 \pm 0.0000)$. High genetic structure was found between two groups $\left(\Phi_{\mathrm{CT}}=0.3093\right)$, but it was not statistically significant $(P=0.09677 \pm 0.01008)$ (Table 4$)$.

Given their genetic homogeneity, the samples from the State of Amazonas were joined in a single group $(\mathrm{MN}+\mathrm{CS}+\mathrm{AU})$ and then compared with the samples from TU and AP (Table 5). The genetic distances (K-2P) between $\mathrm{MN}+\mathrm{CS}+\mathrm{AU}$ and $\mathrm{TU}$ and between TU and A. nuneztovari s.s. were 2.17 and $2.16 \%$, respectively. Oddly, between AP and A. nuneztovari s.s. it was $1.62 \%$. Between the samples of this study and $A$. oswaldoi species $\mathrm{A}$, the genetic distances varied from 6.50 to $7.10 \%$ (three times higher). The genetic distances among the three lineages (Table 6) varied from 1.60 (I and II) to $2.32 \%$ (I and III). Between the three lineages and A. nuneztovari s.s. they ranged from 1.60 to $2.27 \%$, and between the three lineages and $A$. dunhami they ranged from 1.85 to $2.83 \%$. Between A. nuneztovari s.s. and A. dunhami the genetic distance was $2.55 \%$.

The average numbers of nucleotide substitution per site $\left(D_{\mathrm{xy}}\right)$ between lineages were also calculated: I versus II, I versus III and II versus III were $1.60 \% \pm 0.00212$, $2.30 \% \pm 0.00454$ and $1.71 \% \pm 0.00273$, respectively. Lineage I was separated from lineages II and III by zero and five fixed mutations, and two and zero shared mutations, respectively, whereas lineages II and III were separated by seven fixed mutations and 1 shared mutation (Additional file 2). The estimated time of divergence among lineages was of about 0.34 (lineages I and II) to 0.50 (I and III) million years. Between II and III it was $\sim 0.37$ million years (Additional file 2). These estimates indicate that they all diversified in the Pleistocene.

Additional file 3 shows the fixed differences (highlighted in red) among the haplotypes (H16-H18, H21$\mathrm{H} 23$ ) of TU. The fixed differences are defined as sites at which all of the sequences in one sample are different from all of the sequences in a second sample.

Anopheles dunhami was identified for the first time in AU, representing a new record (Table 1) (see [31]).

\section{Microsatellite loci analyses}

A total of 160 individuals encompassing the five samples were genotyped for 12 microsatellite loci (Additional file 4), totaling 1920 genotypes. Most of the loci were polymorphic, with a total of 171 alleles, varying from two (Anu14, Anu15, Anu16) to 25 (Anu6), except the Anu14 locus that was monomorphic in the samples from TU and AP. The Anu6 locus was the most polymorphic one, varying from 12 (TU) to 25 (AU) alleles. The samples from MN, CS and AU had the largest allele numbers $(9.333 ; 8.000 ; 9.083$, respectively) and allele richness $(9.075 ; 7.852 ; 8.887$, respectively) compared with the samples of TU $(7.083 ; 6.922$, respectively) and AP (6.750; 6.568, respectively). Of the 12 loci analysed, 
Table 4 Analysis of molecular variance (AMOVA) for testing the hierarchical population structure within Anopheles nuneztovari s.I. from the Brazilian Amazon region

\begin{tabular}{|c|c|c|c|c|c|c|c|c|}
\hline \multicolumn{5}{|l|}{$\mathrm{COI}$} & \multicolumn{4}{|l|}{ Microsatellites } \\
\hline Groups tested & $\begin{array}{l}\text { Source of varia- } \\
\text { tion components }\end{array}$ & d.f. & $\begin{array}{l}\text { Percentage } \\
\text { variance }(\%)\end{array}$ & Fixation index & $\begin{array}{l}\text { Source of variation compo- } \\
\text { nents }\end{array}$ & d.f. & $\begin{array}{l}\text { Percentage } \\
\text { variance (\%) }\end{array}$ & $\begin{array}{l}\text { Fixation } \\
\text { index }\end{array}$ \\
\hline \multirow{2}{*}{$\begin{array}{l}\text { No grouping (all) MN, } \\
\text { CS, AU, TU, AP }\end{array}$} & Among samples & 4 & 38.00 & \multirow[t]{2}{*}{$\Phi_{S T}=0.3800^{* * *}$} & Among samples & 1 & 8.08 & \multirow[t]{2}{*}{$F_{S T}=0.081^{* * *}$} \\
\hline & Within samples & 98 & 62.00 & & Within samples & 315 & 91.92 & \\
\hline \multirow{3}{*}{$\begin{array}{l}\text { Two groups (1) MN, } \\
\text { CS, AU (2) TU, AP }\end{array}$} & Between groups & 1 & 30.93 & $\Phi_{C T}=0.3093$ & Between groups & 1 & 6.03 & $F_{C T}=0.060$ \\
\hline & $\begin{array}{c}\text { Among samples } \\
\text { within groups }\end{array}$ & 3 & 14.37 & $\Phi_{S C}=0.2081^{* * *}$ & Among samples within groups & 3 & 4.27 & $F_{S C}=0.043^{* * *}$ \\
\hline & Within samples & 98 & 54.70 & $\Phi_{S T}=0.4530^{* * *}$ & Within samples & 315 & 89.70 & $F_{S T}=0.103^{* * *}$ \\
\hline
\end{tabular}

See Table 1 for locality abbreviations

Significance test 10,000 permutations, d.f. degrees of freedom, $\Phi_{S T}$ fixation index within samples, $\Phi_{C T}$ fixation index between regions, $\Phi_{S C}$ fixation index among samples within regions, $F_{S T}$ fixation index within samples, $F_{C T}$ fixation index between regions, $F_{S C}$ fixation index among samples within regions

***P $=0.00000 \pm 0.00000$

Anu4, Аnu10, Anu14 and Anu28 were in HWE for all most of them suggesting heterozygote deficits. LD anal-

Table 5 Values of mean genetic distances (K-2P) and their respective standard errors (mean \pm SE) among the five Anopheles nuneztovari s.l. samples from the Brazilian Amazon region and Anopheles nuneztovari s.s., Anopheles dunhami and the outgroup

\begin{tabular}{|c|c|c|c|c|c|c|}
\hline Samples & $\mathrm{MN}+\mathrm{CS}+\mathrm{AU}$ & Tucuruí & Abacate da Pedreira & A. nuneztovari s.s. & A. dunhami & A. oswaldoi species $A^{*}$ \\
\hline $\mathrm{MN}+\mathrm{CS}+\mathrm{AU}$ & $1.14 \%$ & & & & & \\
\hline Tucuruí & $2.17 \% \pm 0.0042$ & $0.80 \%$ & & & & \\
\hline Abacate da Pedreira & $1.54 \% \pm 0.0035$ & $1.51 \% \pm 0.0036$ & $0.61 \%$ & & & \\
\hline A. nuneztovaris.s. & $2.01 \% \pm 0.0048$ & $2.16 \% \pm 0.0052$ & $1.62 \% \pm 0.0045$ & $0.05 \%$ & & \\
\hline A. dunhami & $2.70 \% \pm 0.0052$ & $2.61 \% \pm 0.0054$ & $2.00 \% \pm 0.0045$ & $2.61 \% \pm 0.0058$ & $1.05 \%$ & \\
\hline A. oswaldoi species $A^{*}$ & $7.10 \% \pm 0.010$ & $6.92 \% \pm 0.0099$ & $6.63 \% \pm 0.0098$ & $6.78 \% \pm 0.010$ & $6.50 \% \pm 0.0094$ & $1.66 \%$ \\
\hline
\end{tabular}

In the diagonal, in italics: mean values intra-samples

MN Manaus, CS Careiro Castanho, AU Autazes, K-2P Kimura-2 Parameters, Mean $\pm S E$ mean (in percentage) and respective standard error

* Outgroup

Table 6 Values of mean genetic distances (K-2P) and their respective standard errors (mean \pm SE) among three Anopheles nuneztovari s.l. lineages from the Brazilian Amazon region and Anopheles nuneztovari s.s., Anopheles dunhami and the outgroup

\begin{tabular}{|c|c|c|c|c|c|c|}
\hline Lineages & Lineage I & Lineage II & Lineage III & A. nuneztovari s.s. & A. dunhami & A. oswaldoi species $A^{*}$ \\
\hline Lineage I & $1.20 \%$ & & & & & \\
\hline Lineage $\|$ & $1.60 \% \pm 0.0044$ & $0.20 \%$ & & & & \\
\hline Lineage III & $2.32 \% \pm 0.0056$ & $1.74 \% \pm 0.0044$ & $0.24 \%$ & & & \\
\hline A. nuneztovari s. s. & $2.00 \% \pm 0.0054$ & $1.60 \% \pm 0.0046$ & $2.27 \% \pm 0.0059$ & $0.15 \%$ & & \\
\hline A. dunhami & $2.67 \% \pm 0.0061$ & $1.85 \% \pm 0.0046$ & $2.83 \% \pm 0.0061$ & $2.55 \% \pm 0.0058$ & $1.30 \%$ & \\
\hline A. oswaldoi species $A^{*}$ & $7.28 \% \pm 0.1012$ & $6.70 \% \pm 0.0095$ & $7.03 \% \pm 0.0098$ & $7.01 \% \pm 0.0096$ & $6.50 \% \pm 0.0094$ & $0.30 \%$ \\
\hline
\end{tabular}

For definition of the lineages, see ML tree topology (Fig. 3)

In the diagonal, in italics: mean values intra-groups

$K-2 P$ Kimura-2 Parameters, Mean $\pm S E$ mean (in percentage) and respective standard error

* Outgroup

samples, whereas the other loci were in disequilibrium in at least one sample. Nineteen $(31.67 \%)$ out of the 60 comparisons exhibited Hardy-Weinberg disequilibrium, ysis was carried out to infer whether these deviations were due to the Wahlund effect, inbreeding, selection, genetic drift, gene flow or null alleles. Forty-one (12.42\%) 
out of 330 exact tests showed significant results for $L D$ $(P=0.00076)$, after Bonferroni correction. Tucuruí had the greatest number of pair-loci (18) with significant test results, followed by AU (9) and CS (8). The other two samples showed three pair-loci, each of them with significant test results. A total of 55 private alleles distributed among the five samples were observed (Additional file 5). Autazes had the highest number of private alleles (17), but at low frequencies. Tucuruí and AP showed less private alleles (10 and 5; respectively); however, they exhibited higher frequencies (allele 218 of the locus Anu6, allele 292 of the Anu12 and allele 218 of the Anu25).

Table 7 shows the genetic differentiation among the samples. As observed for the barcode region analysis, the three samples from the State of Amazonas were genetically similar $\left(F_{\mathrm{ST}}=0.011-0.030\right)$, although the comparisons with AU showed statistically significant differences $(P=0.005)$. Higher and significant values $(P=0.005)$ were observed between the samples from Amazonas and $\mathrm{TU}\left(F_{\mathrm{ST}}=0.110-0.133\right)$, between the samples from Amazonas and $\mathrm{AP}\left(F_{\mathrm{ST}}=0.076-0.103\right)$ and between $\mathrm{TU}$ and $\mathrm{AP}\left(F_{\mathrm{ST}}=0.094\right)$, with a lower level of gene flow $(\mathrm{Nm}=6.05-3.25)$. AMOVA analysis including all samples revealed highly significant structures among them $\left(F_{\mathrm{ST}}=0.081 ; P=0.00000 \pm 0.0000\right)$ (Table 4). The other hierarchical level revealed no significant structure among groups $\left(F_{\mathrm{CT}}=0.060 ; P=0.10178 \pm 0.00339\right)$. There was isolation-by-distance (IBD) among the five samples (Mantel test: $r=0.906 ; P=0.026500$ ), covering a range of $\sim 100-1211 \mathrm{~km}$, indicating that $\sim 90 \%$ of the genetic differentiation observed is explained by geographic distance.

Genetic structure analysis using a Bayesian approach (Fig. 4) identified three biological groups $(K=3)$, based on the highest mean value estimated log probability of data -6119.90 (SD $=7.20)$ and on the value close to the initial "plateau" of the curve, when $K$ was plotted versus the mean posterior probability. These groups corresponded to the three samples from the State of Amazonas (blue), samples from AP (green) and from TU (red). However, five specimens from AU (blue) exhibited a larger proportion of their genomes $(q>0.980$ average of five specimens) assigned to the green group instead of the blue group (Fig. 4). The samples from $\mathrm{MN}$ and CS (group 1) can be considered biologically pure $(Q>0.95$ of belonging to the blue group) and so can those from $\mathrm{TU}$ ( $Q>0.95$ of belonging to the red group). Similarly, FCA analysis clearly separated three groups (Fig. 5), with the sample from TU being the most distant one. BAPS also identified three genetic groups ( $\log M L=-6776.8164$; posterior probability $=1.0$ ) (Additional file 6 ) .

\section{Discussion}

Approximately half of the anopheline malaria vector species belong to sibling/cryptic species complexes [65]. In general, cryptic species [66] are of recent evolutionary origin and may, therefore, be morphologically very similar or identical, making their separation difficult. However, cryptic species can differ genetically, ecologically, behaviourally and epidemiologically. Over time, distinct morphological characters can also evolve; however, morphological differentiation tends to take longer, because changes in morphological traits require changes in multiple genes $[67,68]$. In such a situation, integrated taxonomy with multiple markers is required for an accurate identification.

The two markers used in the present study were sensitive and concordant; both revealed three distinct genetic lineages for A. nuneztovari s.l. from the Brazilian Amazon region. These findings are strong enough to indicate that the populations of $A$. nuneztovari s.l. of this region do not belong to a single panmictic species, confirming previous evidence $[17,18,21-24,31]$.

In the phylogenetic analysis made using only sequences of this study, the ML tree retrieved five monophyletic groups, three of which (I, II, III) were represented by the five samples of this study. Group I was represented by the three samples from the central Amazon region and few specimens from AP. Group II comprised most of the specimens from the northeastern

Table 7 Genetic distances based on the $\mathrm{Nm}$ (above the diagonal) and $\boldsymbol{F}_{\mathrm{ST}}$ (below the diagonal) values among five $A$ nopheles nuneztovari s.I. samples from the Brazilian Amazon region, based on the 12 microsatelite loci

\begin{tabular}{llllll}
\hline Samples & Manaus & Careiro Castanho & Autazes & Tucuruí & Abacate da Pedreira \\
\hline Manaus & - & 43.83 & 15.99 & 3.25 & 4.33 \\
Careiro Castanho & 0.011 & - & 26.34 & 4.06 & 4.74 \\
Autazes & $0.030^{*}$ & $0.019^{*}$ & - & 3.63 & 6.05 \\
Tucuruí & $0.133^{*}$ & $0.110^{*}$ & $0.121^{*}$ & - & 4.82 \\
Abacate da Pedreira & $0.103^{*}$ & $0.100^{*}$ & $0.076^{*}$ & $0.094^{*}$ & - \\
\hline
\end{tabular}

$\mathrm{Nm}$ Mean number of migrant individuals per generation

${ }^{*} P=0.005$, after Bonferroni correction 


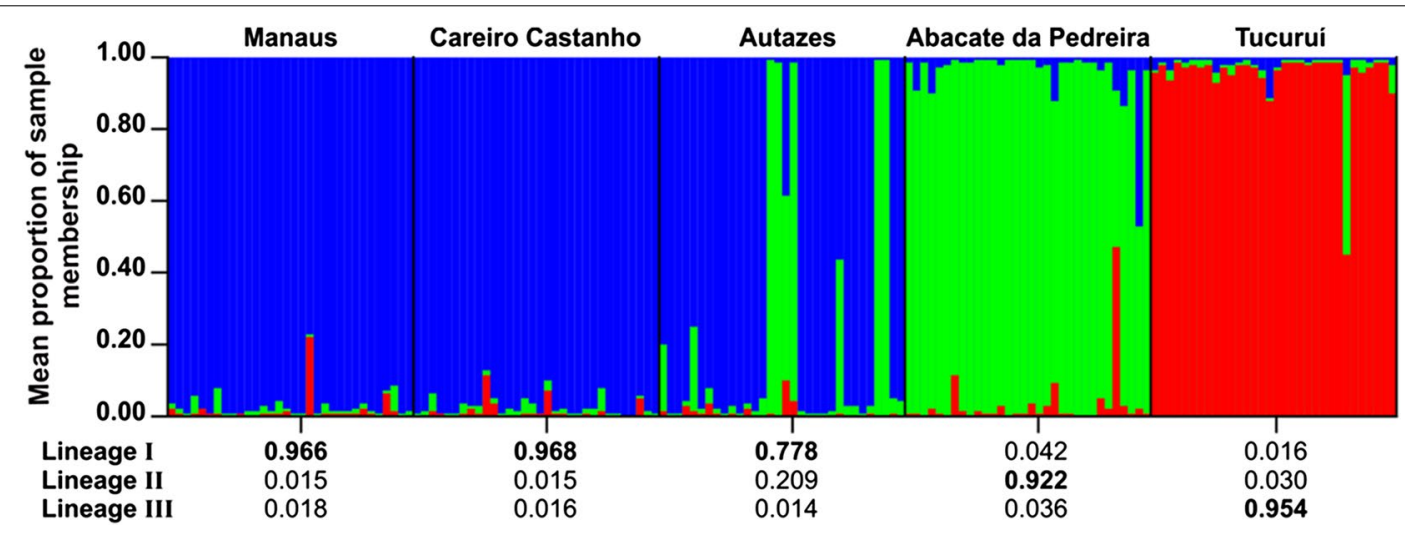

Fig. 4 Bayesian genetic cluster analysis for the five Anopheles nuneztovari s.l. samples from the Brazilian Amazon region. Subdivision of all the individuals into $\mathrm{K}=3$ clusters. Group 1 (blue) comprises the three samples from the State of Amazonas; Group 2 (green) represents the sample of Abacate da Pedreira; Group 3 (red) represents the sample of Tucuruí

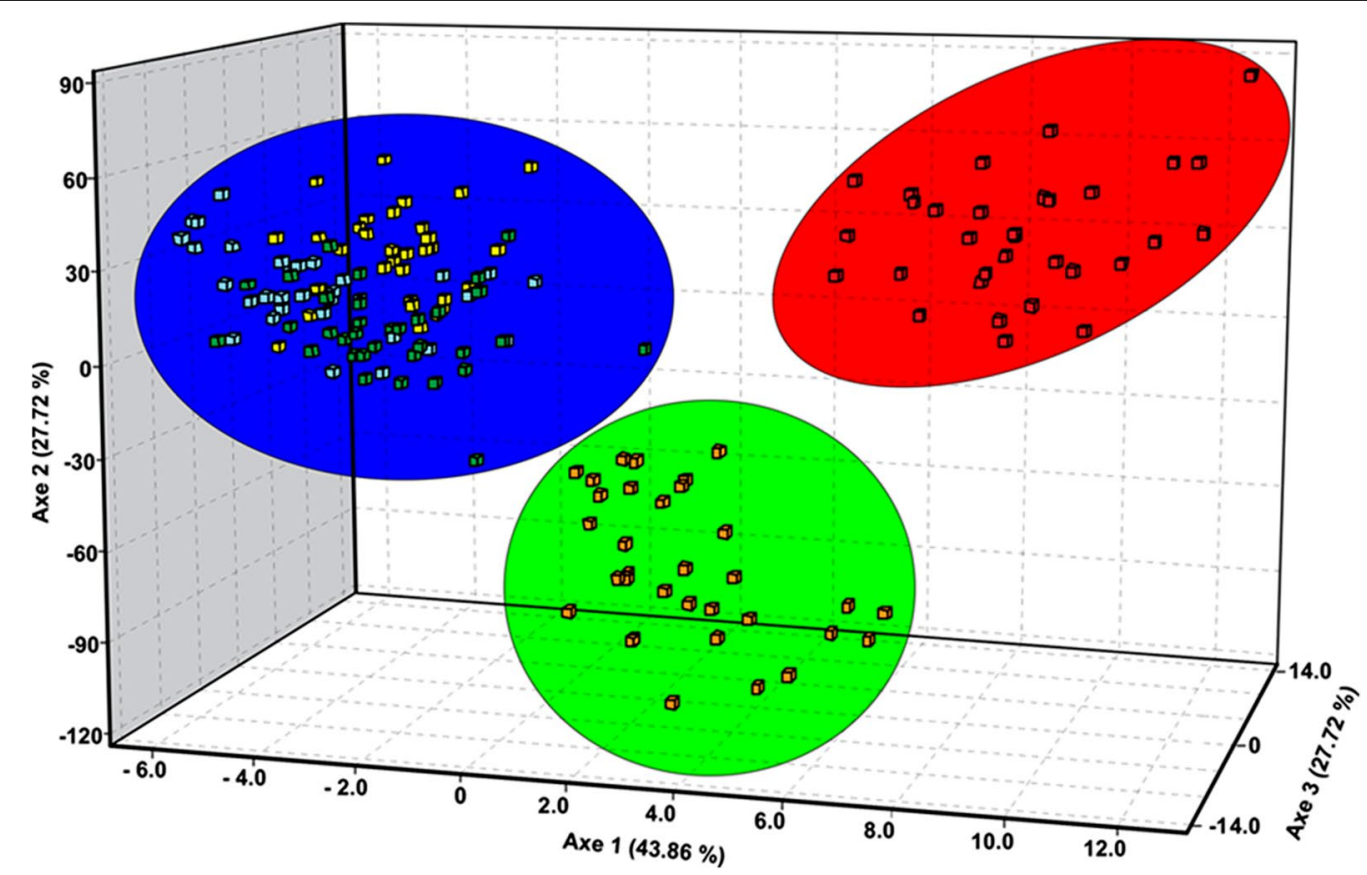

Fig. 5 Factorial correspondence analysis of the five Anopheles nuneztovari s.l. samples from the Brazilian Amazon region, based on the 12 microsatellite loci. Colors represent the biological groups displayed in Fig. 4

region (AP). Group III consisted of specimens from the eastern region (TU). These groups were confirmed by the Bayesian analyses (structure and BAPS) and FCA with microsatellite data.

The groups represented by lineages I and II (A. goeldii) were not well resolved (Fig. 3), likely due to the small number of informative sites between them for this marker (Additional file 3). Furthemore, there were shared haplotypes between AU and AP. The Bayesian analysis with microsatellite data (Fig. 4) showed very similar results; although this analysis clearly separated lineages I and II, five specimens from AU had a larger proportion of their genomes assigned to the AP sample. Taken together, these findings could reflect shared polymorphism or introgression caused by incomplete lineage sorting [65], a phenomenon often observed between young lineages and closely related species $[69,70]$, as may be the case of lineages I and II of this study.

Comparing the dataset of this study with the sequences from GenBank, the ML tree retrieved six groups, four 
of which (I, III, IV, V) were represented by specimens of the five localities of this study plus groups II (A. nuneztovari s.s.) and VI (A. dunhami) (Additional file 1). All sequences from GenBank identified as $A$. goeldii clustered with lineages I and II of this study, suggesting that they represent $A$. goeldii. In this case, $A$. goeldii was paraphyletic. If this is correct, the three groups could represent two or more species within $A$. goeldii. Intriguingly, these data suggest the groups I and III (A. goeldii) and II (A. nuneztovari s.s.) may be same species or incipient species. Supporting these findings, they also presented low genetic distances (1.60-2.0\%). A similar topology (BI tree) was obtained by Scarpassa and Conn [31], who reported that both samples from Bolivia/Colombia/Venezuela and the central region of the Brazilian Amazon clustered to the same major clade II. In contrast, previous studies [22, 24, 25] suggested that they are distinct species. Thus, these results could be explained by incomplete lineage sorting caused by retention of ancestral polymorphism due to the extremely recent divergence of this complex.

On the other hand, lineage III had high support in both ML analyses. Interestingly, no sequence from GenBank identified as $A$. goeldii clustered to lineage III (group IV), suggesting that it does not belong to A. goeldii. Furthermore, although all haplotypes were connected in the haplotype network (Fig. 2), there were no shared haplotypes between this lineage and lineage I, which could indicate some barrier to gene flow. Lineage III can be separated from lineages I and II by five to seven fixed differences, respectively. In the Bayesian analysis (Fig. 4), this lineage was considered biologically pure $(Q>0.95$ of belonging to the red group), and in the FCA analysis (Fig. 5) it was the most distant one. Taken together, the lineage III may represent a new species within the Nuneztovari complex and may be following an evolutionary trajectory independent from the other lineages.

In the present study, the barcode region data indicated very high genetic structure and absence of gene flow $(\mathrm{Nm}<1)$ between the samples of the three regions. In contrast, genetic homogeneity was observed among the three samples from the State of Amazonas (lineage I). Therefore, specimens of these locations may belong to a unique species that is undergoing a differentiation process from lineage II, and distinct from lineage III.

The genetic distances (K-2P) among the three lineages were small (1.60-2.32 \%) and very similar to those reported by Calado et al. [25], who also used the barcode region. However, the distance observed between lineages I and III was similar to those between $A$. albitarsis s.s. and $A$. oryzalimnetes (2.64 \%) of the A. albitarsis complex [36] and between A. dunhami and A. nuneztovari s.s. (2.55-2.61 \%) in this study. Ruiz-Lopes et al. [36] observed a threshold of $2.0 \%$ for separating $A$. albitarsis $\mathrm{H}$ from $A$. marajoara, two sister taxa of the $A$. albitarsis complex, whereas the genetic distance between $A$. triannulatus s.s. and $A$. halophylus/A. triannulatus $C$ varied from 1.7 to $2.30 \%$ [69]. As observed, values $>2.0 \%$ have consistently been reported between sister taxa of species complexes in the Nyssorhynchus subgenus [31, $36,37,69-71]$, whereas the intra-specific divergence is rarely $>2 \%$. These results suggest that the members of A. nuneztovari complex are of recent evolutionary origin, confirming previous studies $[18,31]$. An example of recent divergence was reported in another vector insect, Lutzomyia umbratilis, that likely consists of two cryptic species which showed genetic distances from 0.8 to $1.4 \%$ and moderately supported clades [72], suggesting recent diversification.

Most of the lineages observed in the present study were undetected in the isozymes study [22], except lineage III, likely because of their very recent divergence and the slow evolution rate of this marker for detecting incipient or recently diverged species. However, the sample of TU was the most divergent [22], indicating that its diversification may have started earlier. The results of this study are partially consistent with those obtained by ITS2 [17] and mtDNA-RFLP [18] that identified two groups in the Brazilian Amazon region. This partial disagreement is mainly attributable to differences in sampling strategies between these studies. Our findings, however, match those obtained with the white gene [24]. Lineages I and II of this study correspond to lineage 1 of Mirabello and Conn [24], whereas lineage III corresponds to lineage 4 [24]. This lineage is represented by samples from Altamira (State of Pará) and Areia Branca (State of Rondônia). Altamira is situated near to TU. The authors [24] reported two sympatric lineages, with no heterozygotes observed in either Altamira or Areia Branca. Similarly, the samples from TU and Areia Branca (Rondônia) shared haplotypes and clustered together, both in the haplotype network and in the BI tree analyses [31]. In the present study, an identical situation was observed: most of the specimens from TU clustered in lineage III, whereas the three others clustered in lineage II. Two of these three specimens shared haplotype (H19) with AP, suggesting that two sympatric species might exist in TU: the $A$. goeldii group (lineage II) and a new species (lineage III). The occurrence of two distinct genetic pools in TU could explain the highest number of pair-loci (18) in $L D$ for the microsatellites data, which remained significant after the Bonferroni correction.

The diversification time estimated among the lineages falls in the Pleistocene Epoch (ranging from 0.34 to $0.50 \mathrm{myr}$ ), as previously observed [31], implying divergence within the last one million years. The most 
plausible hypothesis to explain the diversification among the lineages appears to be climatic changes, such as temperature fluctuations, reduced atmospheric $\mathrm{CO}_{2}$ and precipitation, occurred during the Pleistocene and which may have influenced the isolation of these populations in refuge areas, causing the differentiation between them by allopatry. Therefore, the two lineages or species sympatric observed in TU could represent secondary contact zones.

However, previous reports have suggested the Amazon river to be a significant barrier to dispersal for several species [73-75], including anophelines [76, 77]. The sampling of this study was not designed to test the predictions of the riverine barrier hypothesis, but some association may be possible. In this study, the largest differentiation was observed between lineages I and III. MN (lineage I) is situated on the north bank of the Amazon river, whereas CS, AU (both included in lineage I) and TU (lineage III) are located on the south bank. Curiously, mitochondrial and microsatellites markers revealed extensive gene flow, historical and contemporary, between MN and CS/AU, situated in opposite banks. One explanation for this finding is that in these localities the width of the river is not enough to prevent gene flow between populations. Alternatively, the dispersal of these mosquitoes may occur via passive transport, because around these localities, including the $\mathrm{MN}$ area, there is intense river traffic. In contrast, there was no gene flow between these locations and TU. Two interfluves (Xingu and Tapajós rivers) separate AU from TU, whereas three interfluves (Xingu, Tapajós and Madeira rivers) separate $\mathrm{CS}$ from $\mathrm{TU}$, and these three and the Amazon river separate MN from TU. Therefore, it is possible that these interfluves may be acting as dispersal barriers for these anophelines.

Appreciable and significant mitochondrial and microsatellite differentiation was also observed between AP and TU, situated on opposite sides of the Amazon river delta (mouth). In this region, the Amazon river is widest and can reach up to $50 \mathrm{~km}$ in the rainy season. The Amazon river together with the Xingu, Araguaia and Tocantins and other smaller rivers form a large network in this region. This network may act as a dispersal barrier, even porous, restricting the contact between anophelines from the north and south banks, promoting genetic differentiation. Previous studies have reported differentiation between populations of $A$. darlingi $[76,77]$ and $A$. marajoara [71] in this region. On the other hand, the Mantel test showed that $\sim 90 \%$ of the genetic differentiation found among the five localities is explained by IBD, as observed for the white gene [24]. The localities sampled in this study may have influenced these results.
Taken together, the data clearly show that the three genetic lineages studied may be evolving independently in the Brazilian Amazon region. Lineages I and II may represent genetically distinct groups or species within A. goeldii, whereas lineage III may represent a new species and could be the most ancestral one in the Brazilian Amazon region.

Higher levels of intra-population genetic variability, estimated by the microsatellite loci, were detected for the central region (samples from the State of Amazonas) as compared to the samples from TU and AP, supporting previous findings of Scarpassa and Conn [31]. Based on these results, the authors proposed that the central Amazon region is likely to be the ancestral area of this species complex. In the present study, however, the higher level of genetic variability observed may be a consequence of an extensive contemporary gene flow among specimens of the localities of MN, CS and AU, which represent a panmictic population.

\section{Conclusions}

The two markers used in this study were concordant; both revealed three distinct genetic lineages for $A$. nuneztovari s.l. in the Brazilian Amazon region, confirming previous reports. Lineages I and II may consist of genetically distinct groups (likely species) within A. goeldii. Lineage III could represent a new species of the $A$. nuneztovari complex and may be the most ancestral one in the Brazilian Amazon region. Since A. nuneztovari s.l. has been incriminated as a major local malaria vector in the State of Amapá [12], the lineage II $(A$. goeldii) is probably a malaria vector in that area. Furthermore, based on the previous reports $[7,9$, 13] the lineage I (A. goeldii) likely may be involved in the malaria transmission in the central region from the Brazilian Amazon. The involvement of lineage III in the malaria transmission remains to be clarified. This study highlights the importance of utilizing integrative approaches for separate lineages and species of this complex, in order to achieve accurate results.

\section{Additional files}

\footnotetext{
Additional file 1: Maximum Likelihood (ML) topology tree of the 27 Anopheles nuneztovari s.l. haplotypes from the Brazilian Amazon region, two Anopheles nuneztovari s.s. haplotypes $(\mathrm{H} 28, \mathrm{H} 29)$ and three Anopheles dunhami haplotypes $(\mathrm{H} 31, \mathrm{H} 32, \mathrm{H} 33)$ and sequences downloaded from GenBank, using the GTR + I+G nucleotide substitution model. Values above each branch represent bootstrap support. Anopheles oswaldoi species A was used as outgroup.

Additional file 2: Average numbers of nucleotide substitution per site $\left(D_{x y}\right)$, mean number of nucleotide differences $(K)$, and the estimated time of divergence among the Anopheles nuneztovari s.l. lineages from the Brazilian Amazon region. * Sequence divergence estimates are given in percentage; divergence time estimates are given in million years, using mutation rates of $2.3 \%$.
} 
Additional file 3: Variable sites among 27 Barcode region haplotypes observed for Anopheles nuneztovari s.l. from the Brazilian Amazon region. H, Haplotypes.

Additional file 4: Intra-population genetic diversity measures calculated for the five Anopheles nuneztovari s.l. samples from the Brazilian Amazon region, based on the 12 microsatellite loci. $N_{A^{\prime}}$ Allele number; $A_{R^{\prime}}$ Allele richness; $H_{0}$, observed heterozygosity; $H_{E}$, expected heterozygosity; $r$, estimated frequency of null alleles; $F_{I S}$, inbreeding coefficient; -, no significant heterozygote deficiency; mono, monomorphic. The values in bold indicate Hardy-Weinberg disequilibrium at the loci, after Bonferroni correction $(P=0.004)$

Additional file 5: Private alleles observed in the five samples of Anopheles nuneztovari s.l. from the Brazilian Amazon region.

Additional file 6: Bayesian analysis of population structure (BAPS) of the five Anopheles nuneztovari s.l. samples from the Brazilian Amazon region, using 12 microsatellite loci. Dataset analysis obtained from 160 specimens indicated the existence of three genetic clusters. Subdivision of all the specimens into $\mathrm{K}=3$ clusters. Cluster 1 (blue) comprises the specimens of three samples from the State of Amazonas; Cluster 2 (green) represents the sample from Abacate da Pedreira; Cluster 3 (red) represents the sample from Tucuruí.

\section{Authors' contributions}

VMS designed the study. VMS, JFS collected the anopheline specimens in the field and identified them. VMS and ASCM generated and analysed the data. VMS wrote the manuscript. ASCM edited the manuscript. All authors read and approved the final manuscript.

\section{Author details}

${ }^{1}$ Laboratório de Genética de Populações e Evolução de Mosquitos Vetores de Malária e Dengue, Coordenação de Biodiversidade, Instituto Nacional de Pesquisas da Amazônia (INPA), Avenida André Araujo, 2936. Bairro Petrópolis, Manaus, Amazonas 69067-375, Brazil. ${ }^{2}$ Programa de Pós-Graduação em Genética, Conservação e Biologia Evolutiva, Instituto Nacional de Pesquisas da Amazônia (INPA), Avenida André Araujo, 2936. Bairro Petrópolis, Manaus, Amazonas 69067-375, Brazil.

\section{Acknowledgements}

This study was funded by MCTI/INPA and by grants from the Amazonas Research Foundation (FAPEAM), process numbers 1501/2008 and 3111/2012-Universal, granted to VMS, from the INCT-CENBAM/CNPq/FAPEAM/ INPA granted to William Ernest Magnusson, and from the PRO-EQUIPAMENT/ CAPES, Brazil. ASCM had a scholarship (DCTA-C) from FAPEAM-Universal Amazonas (process number 3111/2012) granted to VMS. The authors thank Dr. Ronildo B. Alencar by discussions in the phylogenetic analyses. The authors thank also the two anonymous reviewers who significantly improved this manuscript.

\section{Competing interests}

The authors declare that they have no competing interests.

Received: 27 November 2015 Accepted: 5 March 2016 Published online: 12 April 2016

\section{References}

1. Faran ME. Mosquito studies (Diptera, Culicidae). XXXIV. A revision of the Albimanus section of the subgenus Nyssorhynchus of Anopheles. Contrib Am Entomol Inst (Ann Arbor). 1980;15:1-215.

2. Fleming G. Biology y ecologia de los vectores de la malaria en las Americas PAHO/WHO. Washington: PNSP-86-72; 1986. p. 54

3. Sinka ME, Rubio-Palis Y, Manguin S, Patil AP, Temperley WH, Gething PW, et al. The dominant Anopheles vectors of human malaria in the Americas: occurrence data, distribution maps and bionomic précis. Parasit Vectors. 2010;3:72.
4. Gabaldón A. Anopheles nuneztovari: importante vector y agente de malaria refractaria en Venezuela. Boletin de la Direccion de Malariologica y Saneamiento Ambiental. 1981;21:28-38.

5. Gutiérrez LA, Gonzáles JJ, Gómez GF, Castro MI, Rosero DA, Luckhart $\mathrm{S}$, et al. Species composition and natural infectivity of anthropophilic Anopheles (Diptera: Culicidae) in the states of Córdoba and Antioquia, Northwestern Colombia. Mem Inst Oswaldo Cruz. 2009;104:1117-24.

6. Arruda M, Carvalho MB, Nussenzweig RS, Maracic M, Ferreira AW, Cochrane AH. Potential vectors of malaria and their different susceptibility to Plasmodium falciparum and Plasmodium vivax in northern Brazil identified by immunoassay. Am J Trop Med Hyg. 1986;35:873-81.

7. Tadei WP, Santos JMM, Scarpassa VM, Rodrigues IB. Incidência, distribuição e aspectos ecológicos de espécies de Anopheles (Diptera: Culicidae), em regiões naturais e sob impacto ambiental da Amazônia brasileira. In: Bases Científicas para Estratégias de Preservação e Desenvolvimento da Amazônia. Ferreira EJG, Santos GM, Leão ELM, Oliveira LA, editors. Vol. 2. Manaus: Instituto Nacional de Pesquisas da Amazônia. 1993, p. 167-196.

8. Tadei WP, Dutary-Thatcher B, Santos JMM, Scarpassa VM, Rodrigues IB, Rafael MS. Ecologic observations on anopheline vectors of malaria in the Brazilian Amazon. Am J Trop Med Hyg. 1998;59:325-35.

9. Tadei WP, Dutary-Thatcher B. Malaria vectors in the Brazilian Amazon: Anopheles of the subgenus Nyssorhynchus. Rev Inst Med Trop S Paulo. 2000:42:87-94.

10. Póvoa MM, Wirtz RA, Lacerda RNL, Miles MA, Warhurst D. Malaria vectors in the municipality of Serra do Navio, State of Amapá, Amazon Region. Brazil. Mem Inst Oswaldo Cruz. 2001;96:179-84.

11. Silva-Vasconcelos A, Kató MYN, Mourão EM, Souza RTL, Lacerda RNL, Sibajev A, et al. Biting indices, host-seeking activity and natural infection rates of anopheline species in Boa Vista, Roraima, Brazil from 1996 to 1998. Mem Inst Oswaldo Cruz. 2002;97:151-61.

12. Galardo ACR, Arruda M, Couto ARA, Wirtz R, Lounibos LP, Zimmerman RH. Malaria vectors incrimination in three rural riverine villages in the Brazilian Amazon. Am J Trop Med Hyg. 2007;76:461-9.

13. Rios-Velásques CM, Martins-Campos KM, Simões RC, Izzo T, Santos EV, Pessoa FAC, et al. Experimental Plasmodium vivax infection of key Anopheles species from the Brazilian Amazon. Malar J. 2013;12:460.

14. Elliott R. The influence of vector behavior on malaria transmission. Am J Trop Med Hyg. 1972;21:755-63.

15. Kitzmiller JB, Kreutzer RD, Tallaferro E. Chromosomal differences in populations of Anopheles nuneztovari. Bull World Health Org. 1973;48:435-45.

16. Conn J, Puertas YR, Seawright JA. A new cytotype of Anopheles nuneztovari from Western Venezuela and Colombia. J Am Mosq Control Assoc. 1993:9:294-301.

17. Fritz GN, Conn J, Cockburn AF, Seawright JA. Sequence analysis of the ribosomal DNA internal transcribed spacer 2 from populations of Anopheles nuneztovari (Diptera: Culicidae). Mol Biol Evol. 1994;11:406-16.

18. Conn JE, Mitchell SE, Cockburn AF. Mitochondrial DNA analysis of the neotropical malaria vector Anopheles nuneztovari. Genome. 1998;41:313-27.

19. Hribar LJ. Geographic variation of male genitalia of Anopheles nuneztovari (Diptera: Culicidae). Mosq Syst. 1994;26:132-44.

20. Linley JR, Lounibos LP, Conn J, Duzak D, Nishimura N. A description and morphometric comparison of eggs from eight geographic populations of the South American malaria vector Anopheles (Nyssorhynchus) nuneztovari (Diptera: Culicidae). J Am Mosq Control Assoc. 1996;12:275-92.

21. Scarpassa VM, Tadei WP, Suarez MF. Allozyme differentiation among allopatric populations of Anopheles nuneztovari (Diptera: Culicidae). Braz J Genet. 1996;19:265-9.

22. Scarpassa VM, Tadei WP, Suarez MF. Population structure and genetic divergence in Anopheles nuneztovari (Diptera: Culicidae) from Brazil and Colombia. Am J Trop Med Hyg. 1999;60:1010-8.

23. Scarpassa VM, Geurgas S, Azeredo-Espin AML, Tadei WP. Genetic divergence in mitochondrial DNA of Anopheles nuneztovari (Diptera: Culicidae) from Brazil and Colombia. Genet Mol Biol. 2000;23:71-8.

24. Mirabello L, Conn JE. Population analysis using the nuclear white gene detects Pliocene/Pleistocene lineage divergence within Anopheles nuneztovari in South America. Med Vet Entomol. 2008;22:109-19.

25. Calado DC, Foster PG, Bergo ES, Santos CLS, Galardo AKR, Sallum MAM. Resurrection of Anopheles goeldii from synonymy with Anopheles nuneztovari (Diptera: Culicidae) and a new record for Anopheles dunhami in the Brazilian Amazon. Mem Inst Oswaldo Cruz. 2008:103:791-9. 
26. Scarpassa VM. Divergência genética entre populações alopátricas de Anopheles nuneztovari Gabaldón, 1940 (Diptera: Culicidae) do Brasil e Colômbia. Doutoral Thesis. Instituto Nacional de Pesquisas da Amazônia, Manaus, Brazil. 1996;p. 171.

27. Sant'Ana DC, Bergo ES, Sallum MAM. Anopheles goeldii Rozeboom and Gabaldón (Diptera: Culicidae): a species of the Nuneztovari Complex of Anopheles Meigen. Rev Brasil Entomol. 2015;59:68-76.

28. Foster PG, Bergo ES, Bourke BP, Oliveira TMP, Nagaki SS, Sant'Ana DC, et al. Phylogenetic analysis and DNA-based species confirmation in Anopheles (Nyssorhynchus). PLoS One. 2013;8:e54063.

29. Lounibos LP, Wilkerson RC, Conn JE, Hribar LJ, Fritz GN, Danoff-Burg JA Morphological, molecular, and chromosomal discrimination of cryptic Anopheles (Nyssorhynchus) (Diptera: Culicidae) from South America. J Med Entomol. 1998;35:830-8.

30. Trindade DB, Scarpassa VM. Genetic differentiation and diagnostic loci among Anopheles (Nyssorhynchus) rangeli, An. (Nys.) nuneztovari and An. (Nys.) dunhami (Diptera: Culicidae) from the Brazilian Amazon. J Med Entomol. 2002;39:613-20.

31. Scarpassa VM, Conn JE. Mitochondrial DNA detects a complex evolutionary history with Pleistocene Epoch divergence for the Neotropical malaria vector Anopheles nuneztovari sensu lato. Am J Trop Med Hyg. 2011;85:857-67.

32. Ruiz F, Linton Y-M, Ponsonby DJ, Conn JE, Herrera M, Quiñones ML, et al. Molecular comparison of topotypic specimens confirms Anopheles (Nyssorhynchus) dunhami Causey (Diptera: Culicidae) in the Colombian Amazon. Mem Inst Oswaldo Cruz. 2010;105:899-903.

33. Causey OR. Description of Anopheles (Nyssorhynchus) dunhami, a new species from the Upper Amazon Basin. J Nat Malar Soc. 1945;4:231-5.

34. Loaiza JR, Bermingham E, Sanjur OI, Scott ME, Bickersmith SA, Conn JE. Review of genetic diversity in malaria vectors (Culicidae: Anophelinae). Infect Genet Evol. 2012;12:1-12.

35. Hebert PDN, Ratnasingham S, deWaard JR. Biological identification through DNA barcode. Proc R Soc Lond B. 2003;270:313-22.

36. Ruiz-Lopes F, Wilkerson RC, Conn JE, Mckeon SN, Levin DM, Quiñones ML, et al. DNA barcoding reveals both known and novel taxa in the Albitarsis group (Anopheles: Nyssorhynchus) of Neotropical malaria vectors. Parasit Vectors. 2012;5:44.

37. Ruiz-Lopes F, Wilkerson RC, Ponsonby DJ, Herrera M, Sallum MAM, Veléz ID, et al. Systematic of the Oswaldoi complex (Anopheles, Nyssorhynchus) in South America. Parasit Vectors. 2013;6:324.

38. Foley DH, Wilkerson RC, Cooper RD, Volovsek ME, Bryan JH. A molecular phylogeny of Anopheles annulipes (Diptera: Culicidae) sensu lato: The most species-rich anopheline complex. Mol Phylogenet Evol. 2007:43:283-97.

39. Austin JD, Bertin A, Bórques JP, Cardoza TB, Douglas KC, Ellwood SR, et al. Molecular ecology resources primer development consortium Permanent Genetics Resources added to Molecular Ecology Resources Database 1 Feb 2011-31 Mar 2011. Mol Ecol Res. 2011;11:757-8 (Print).

40. Cunha-Machado AS, Scarpassa VM. New microsatellite markers for the neotropical malaria vector Anopheles nuneztovari sensu lato. Genet Mol Res. 2014;13:8856-61. doi:10.4238/2014.October.27.26.

41. Cova-Garcia P. Notas sobre los anofelinos de Venezuela y su identificación. Ed. Grafos, Caracas. 1961

42. Sambrook J, Russell DW. A Laboratory Manual 2001. New York: Cold Spring Harbor Laboratory Press.

43. Folmer O, Black M, Hoeh W, Lutz R, Vrijenhoek R. DNA primers for amplification of mitochondrial Cytochrome C Oxidase subunit I from diverse metazoan invertebrates. Mol Mar Biol Biotechnol. 1994;3:294-9.

44. Schuelke M. An economic method for the fluorescent labeling of PCR fragments. Nat Biotechnol. 2000;18:233-4.

45. Hall TA. BioEdit: a user-friendly biological sequence alignment editor and analysis program for Windows 95/98/NT. Nucl Acids Symp Ser. 1999;41:95-8

46. Chromas Lite ${ }^{\circledR}$ Program. http://www.technelysium.com.au. Accessed 18 Jul 2014.

47. BLAST (Basic Local Alignment Search Tool). http://www.ncbi.nlm.nih.gov/ BLAST. Accessed 18 Jul 2014.

48. Librado P, Rozas J. DnaSP v. 5: a software for comprehen-sive analysis of DNA polymorphism data. Bioinformatics. 2009;25:1451-2.
49. Clement M, Posada D, Crandall KA. TCS: a computer program to estimate gene genealogies. Mol Ecol. 2000;9:1657-60.

50. Tamura K, Stecher G, Peterson D, Filipski A, Kumar S. MEGA6: Molecular Evolutionary Genetics Analysis version 6.0. Mol Biol Evol. 2013;30:2725-9.

51. Posada D. jModelTest: phylogenetic model averaging. Mol Biol Evol. 2008:25:1253-6.

52. Excoffier L, Laval G, Schneider S. An integrated software package for population genetics data analysis, Version 3.01. Computational and Molecular Population Genetics Lab. Institute of Zoology, University of Berne, Switzerland. 2006. http://www.cmpg.unibe.ch/software/arlequin3. Accessed 18 Jul 2014.

53. Tajima F. Statistical method for testing the neutral mutation hypothesis by DNA polymorphisms. Genetics. 1999;123:585-95.

54. Fu YX, Li WH. Statistical tests of neutrality of mutations. Genetics. 1993;133:693-709.

55. Fu YX. Statistical tests of neutrality of mutations against population growth, hitchhiking and background selection. Genetics. 1997; 147:915-25.

56. Brown A. Rapid morphological radiation and convergence among races of the butterfly Heliconius erato inferred from patterns of mitochondrial DNA evolution. Proc Natl Acad Sci USA. 1994;91:6491-5.

57. Van Oosterhout C, Hutchinson WF, Willis DPM, Shipley P. Micro-checker: software for identifying and correcting genotyping errors in microsatellite data. Mol Ecol Notes. 2004;4:535-8.

58. Peakall R, Smouse PE. GenAlEx 6.5: genetic analysis in Excel. Population genetic software for teaching and research-an update. Bioinformatics. 2012;28:2537-9.

59. Goudet J. FSTAT 2.9.3.2: A program to estimate and test gene diversities and fixation indices. 2002. http://www2.unil.ch/popgen/softwares/fstat. htm. Accessed at 6 Jan 2015

60. Pritchard JK, Stephens M, Donnelly P. Inference of population structure using multilocus genotype data. Genetics. 2000;155:945-59.

61. Falush D, Stephens M, Pritchard JK. Inference of population structure using multilocus genotype data: linked loci and correlated allele frequencies. Genetics. 2003;164:1567-87.

62. Belkhir K, Borsa P, Chikhi L, Raufaste N, Bonhomme F. GENETIX 4.05, logiciel sous Windows TM pour la génétique des populations. Laboratoire Génome, Populations, Interactions, CNRS UMR 5000, Université de Montpellier II, Montpellier (France) 1996-2004. http://kimura.univ-montp2.fr/ genetix/. Accessed at $17 \mathrm{Jul} 2015$.

63. Corander J, Marttinen P, Sirén J, Tang J. Enhanced Bayesian modelling in BAPS software for learning genetic structures of populations. BMC Bioinformatics. 2008;9:539.

64. Holm S. A simple sequential rejective multiple test procedure. Scandinavian J Statistics. 1979;6:65-70.

65. Krzywinski J, Besansky NJ. Molecular systematics of Anopheles: from subgenera to subpopulations. Annu Rev Entomol. 2003;48:111-39.

66. Mayr E. Systematics and the origin of species. New York: Columbia University Press; 1942.

67. Ridley M. Evolution. 3rd edition. Malden: Blackwell Publishing; 2004.

68. Coyne JA, Orr HA. Speciation. Sunderland: Sinauer Associates Inc; 2004.

69. Moreno M, Bickersmith S, Harlow W, Hildebrandt J, McKeon SN, Silvado- Nascimento TF, et al. Phylogeography of the neotropical Anopheles triannulatus complex (Diptera: Culicidae) supports deep structure and complex patterns. Parasit Vectors. 2013;6:47.

70. Bourke BP, Oliveira TP, Suesdek L, Bergo ES, Sallum MAM. A multi-locus approach to barcoding in the Anopheles strodei subgroup (Diptera: Culicidae). Parasit Vectors. 2013;6:111.

71. McKeon SN, Lehr MA, Wilkerson RC, Ruiz JF, Sallum MA, Lima JB, et al. Lineage divergence detected in the malaria vector Anopheles marajoara (Diptera: Culicidae) in Amazonian Brazil. Malar J. 2010;9:271.

72. Scarpassa VM, Alencar RB. Molecular taxonomy of the two Leishmania vectors Lutzomyia umbratilis and Lutzomyia anduzei (Diptera: Psychodidae) from the Brazilian Amazon. Parasit Vectors. 2013;6:258.

73. Funk W, Caldwell J, Peden C, Padial JM, De la Riva I, Cannatella DC. Tests of biogeographic hypotheses for diversification in the Amazon forest frog, Physalaemus petersi. Mol Phyl Evol. 2007;44:825-37.

74. Hayes F, Sewlal J. The Amazon River as a dispersal barrier to passerine birds: effects of river width, habitat and taxonomy. J Biogeography. 2004;31:1809-18. 
75. Scarpassa VM, Alencar RB. Lutzomyia umbratilis, the main vector of Leishmania guyanensis, represents a novel species complex? PLoS One. 2012;7:e37341. doi:10.1371/journal.pone.0037341.

76. Pedro PM, Sallum MAM. Spatial expansion and population structure of the neotropical malaria vector, Anopheles darlingi (Diptera: Culicidae). Biol J Linnean Soc. 2009;97:854-66.
77. Conn JE, Vineis J, Bollback J, Onyabe DY. Population structure of the malaria vector Anopheles darlingi in a malaria-endemic region of eastern Amazonian Brazil. Am J Trop Med Hyg. 2006;74:798-806.
Submit your next manuscript to BioMed Central and we will help you at every step:

- We accept pre-submission inquiries

- Our selector tool helps you to find the most relevant journal

- We provide round the clock customer support

- Convenient online submission

- Thorough peer review

- Inclusion in PubMed and all major indexing services

- Maximum visibility for your research

Submit your manuscript at www.biomedcentral.com/submit
(O) Biomed Central 